tion, while curious lacunae appear, in spite of the 571 references. Thus in reviewing changes in RNA and protein with stimulation, no mention is made of the autoradiographic studies of Watson, for example. Dealing with "transfer by injection", Bogoch gives the impression that all these studies involve the use of RNA fractions; in fact, many recent claims revolve around the use of brain proteins or polypeptides. Little attention is paid to the anatomical correlates of behavioural and biochemical changes, at dendritic or synaptic level. This portion of the book, however, is a useful review and a source of references.

The second half of the book (two chapters) is largely eoncerned with Bogoch's own results in the field of the brain mucoids. Here there is a wealth of experimental detail, by contrast with the paucity in the first half of the book (thin-layer chromatography, for instance, was performed on "carefully cleaned" glass plates on page 197), and there are 40 references to the author's own work (13 to abstracts or unpublished results). Most of this relates to the author's considerable achievement in partially characterizing and fractionating the brain mucoids (a few structural formulae might help the uninitiated). He makes a strong case for the recognition of the considerable degree of individual variations within a species which can be observed among these complex molecules, and he is obviously justified in drawing their coding potential to the attention of theorists of brain mechanisms. Little of this work is directly relevant to the issue of memory mechanisms as such, however, and those experiments by the author which suggest that changes occur in the pattern and quantity of some mucoid fractions during learning in pigeons, while of considerable interest, do not perhaps warrant the weight of hypothesis placed upon them, although they do serve the function of presenting all of Bogoch's work in this area in a form accessible to other workers in the field. It would, however, be incautious to recommend this book as a sole introduction to the theme of its title to students or others not dircetly researching in the area. Steven P. R. Rose

\section{LIVING POLYMERS}

\section{Carbanions, Living Polymers and Electron-Transfer Processes}

By M. Szware. Pp. xvi+695. (Wiley (Interscience) : New York and London, January 1969.) $260 \mathrm{~s}$.

THE advance of science proceeds by the constant attrition of the immediate barriers to knowledge, and by dramatic impetus of a new discovery of some unsuspected phenomenon. Occasionally, an apt title or description of such a phenomenon captures the imagination of the seientific public and in doing so ensures a place in history for a given worker. Less frequently, the apt title proves to have connotation beyond the closer confines of the original area of interest. Elements of all these matters are reflected in the work and scholarship of Professor Szwarc, and perhaps more particularly are mirrored in his book Carbanions, Living Polymers and Electron-Transfer Processes.

After an introductory chapter, the application of living polymers to synthetic polymer chemistry is described. The properties of living polymers are discussed and there is mention of their relevance to block, graft, starand comb-shaped polymers. Chapters on the thermodynamics of propagation, on ions, ion-pairs and their agglomerates, and on radical-ions, solvated electrons, and electron transfer processes, are shared with a detailed chapter on experimental techniques in kinetic studies of anionic polymerization. These chapters, incidentally, serve to emphasize the writer's authority in his subject. The same can be said of succeeding chapters on propagation of anionic polymerization, on anionic poly- merization in systems involving lithium counterions, and on the kinetics of anionic copolymerization. Suggestions of wider connotations will arise from accounts of NCA polymerization to poly-amino acids and of helical polymerization. The book concludes, fittingly, with a chapter on termination of polymerization. Ample references follow each chapter and the recent dates of many of these, together with substantial mention of unpublished work and private communication, confirm the effort which has elearly gone into the preparation of this work. 'There are, of course, also author and subject indices.

Viewed overall, the publication is well printed and contains adequate figures and tables, together with line diagrams of laboratory seale equipment and techniques. It is a book which will have the greatest appeal to the research chemist, and not one who is necessarily engaged on studies of polymerization, although this is obviously the main field of interest. It should prove of value to advanced course students of polymer chemistry. On the other hand, in view of the brevity of technological aspects, the industrial chemist may be somewhat disappointed, despite the mention of thermoplastic elastomers; but even here it should be remembered that the substance is comparatively new and for such a person a perusal might indeed prove to be an investment. To the research worker and the academic, however, this book will bo quickly appreciated as a valuable contribution by a distinguished author.

R. P. SHELDON

\section{POTENTIOMETRY}

\section{Chemical Applications of Potentiometry}

By Hazel Rossotti. Pp. xiv +229. (Van Nostrand: Princeton, New Jersey, and London. January 1969.) $75 s$.

The word "Potentiometry" in the title of this book is to be interpreted as measurement of the e.m.f. of an electrochemical cell with reversible electrodes. The cell may include liquid junctions, or may be non-isothermal. but the measurement and significance of electrode poten. tial in studies of electrode kinetics or corrosion, and topies such as "chronopotentiometry", are excluded from consideration.

The book therefore deals with a field which is fairly extensively treated in the standard textbook of electrochemistry, and the first few chapters, in particular, duplicate material which can be found elsewhere-for example, thermodynamics of cells, standard e.m.f.s, sign conven. tions, classification of cell types. But it should be added that this account does pay more attention than most to the sort of cell which is actually used in the vast majority of potentiometric studies, that is, a cell with a salt bridge or equivalent device, and quite often a very high ionic strength throughout.

The level of these early chapters is fairly elementary and they should not present difficulties to first or second year undergraduates. The "applications" considered naturally include $p \mathrm{H}$ determinations and the evaluation of thermodynamic data, and chapter six gives an interest. ing discussion of the stability of intermediate oxidation states with respect to disproportionation, and of predominance areas on potential- $p \mathrm{H}$ diagrams.

Some of the later chapters (from chapter ton onwards) are more specialized and give more details of certain applications - notably acid-base equilibria (including poly basic acids), metal ion complexes and potentiometric titrations. Chapters thirteen, fourteen and fifteen deal respectively with cells containing solvents other than water, fused salts and solid electrolytes. They cover a wide range of topics and incorporate much interesting information which is not conveniently compiled elsewhere. For the most part, the mathematics and thermodynamies remain quite elementary and should not prove too difficult 